\title{
Phase Modification of Acrylate Rubber/Chlorinated Polypropylene Blends by a Hindered Phenol Compound
}

\author{
Chifei Wu, ${ }^{\dagger}$ Yoshio Otani, Norikazu Namiki, Hitoshi Emi, and Koh-hei NitTA ${ }^{*}$ \\ Department of Chemistry and Chemical Engineering, Kanazawa University, \\ 2-40-20 Kodatsuno, Kanazawa, Ishikawa 920-8667, Japan \\ ${ }^{*}$ School of Materials Science, Japan Advanced Institute of Science and Technology, Ishikawa 923-1292, Japan
}

(Received October 5, 2000; Accepted January 16, 2001)

\begin{abstract}
The dynamic mechanical properties and the morphologies for the binary blends of acrylate rubber $(\mathrm{ACM})$ and chlorinated polypropylene (CPP) with 3,9-bis[1,1-dimethyl-2\{ $\beta$-(3-tert-butyl-4-hydroxy-5-methylphenyl)propionyloxy\}ethyl]-2,4,8,10-tetraoxaspiro[5,5]-undecane (AO-80), and their ternary systems were investigated. The AO80 distribution to each phase of an immiscible ACM/CPP blend was studied in term of a shift in glass-transition temperature. It was found that when the AO-80 content is lower than 30\% the AO-80 molecules are preferentially dissolved to an $\mathrm{ACM}$ continuous phase, whereas as the $\mathrm{AO}-80$ content increases, a part of $\mathrm{AO}-80$ molecules are incorporated to the blend interfaces, and then to the domains of CPP. In addition, the reduction in the domain size of CPP due to adding AO80 was also observed. A ternary blend of ACM/CPP (7:3) with AO-80 (35\%) showed a novel tan $\delta$ peak between two peaks corresponding to ACM and CPP. This peak is attributed to an interfacial layer where a super-molecular network is formed. As a result, a ternary blend of $\mathrm{ACM} / \mathrm{CPP}$ with $\mathrm{AO}-80$ was found to be a very good damping material.

KEY WORDS Polymer Blend / Acrylate Rubber / Chlorinated Polypropylene / Hindered Phenol / Interface / Dynamic Mechanical Property / Damping Property /
\end{abstract}

The individual phases in immiscible polymer blends often retain their physical properties. Multiphase polymer blends therefore offer unique possibilities to improve some properties of pure components. ${ }^{1}$ Unfortunately, the morphology of the multiphase blends for the improvement of mechanical properties is often difficult to control. Block and graft copolymers were widely used as compatibilizers for the improvement of morphology of immiscible polymer blends. Modification of the polymer blends by adding properly selected polymeric compatibilizers generally provides better dispersion and increased interfacial adhesion, leading to improvement of the mechanical properties. The success of this concept has been reviewed in a number of articles. ${ }^{2,3}$

On the other hand, low-molecular-weight compound are widely used in rubber industries to improve or control the mechanical properties, viscoelastic behavior, and processability. Very few fundamental studies have been reported on the factors and mechanism of these improvements in polymer blends. According to our recent studies, ${ }^{4-10}$ the addition of hindered phenols can lead to the discovery of some unknown functions and the modification of mechanical properties of some partially polarized polymers such as chlorinated polyethylene (CPE) and acrylate rubber (ACM). Adding AO-80 into $\mathrm{CPE}$ causes a novel transition that appeared above the glass transition temperature of $\mathrm{CPE} .{ }^{4-8}$ In addition, we found that such as broad damping properties ${ }^{7,8}$ and shapememory effects ${ }^{4}$ were accompanied by this novel transition. In particular, AO-80 was found to improve compatibility of CPE/ACM blends, and to act as a new type of compatibilizer. ${ }^{8}$ This is due to formation of a supermolecular network where CPE and ACM couples by AO80 that is a bi-functional hydrogen bonding acceptor. The existence of hydrogen bonding between hydroxyl groups of AO-80 and carbonyl groups of ACM or $\alpha$ hydrogen of CPE was confirmed by infrared spectrum.

ACM and CPP exhibited a relatively high $\tan \delta$ value $(>2)$, their blends therefore has a possibility to use for damping materials. ${ }^{11}$ However, those $\tan \delta$ curves have shown limited damping capability as indicated by two narrow peaks. This is because the blends of ACM and CPP are immiscible. To obtain a very broad transition range with high value for the area under the $\tan \delta$ curve, it is of great importance to modify the compatibility of ACM/CPP blends. AO-80 was found to heighten the $\tan \delta$ value of ACM and CPP, indicating that AO-80 interact strongly with both ACM and CPP. Consequently adding such AO-80 containing two hydrogen-bonding acceptors into their blends makes it possible to compatibilize ACM and CPP phase.

In the case of the phase-separated ionomers, it is generally observed that the low-molecular-weight compounds as a plasticizer are preferentially distributed into either matrix or the cluster phase. ${ }^{12-18}$ However, in present study, to act AO-80 as a compatibilizer, it is necessary to control the AO- 80 distribution into an interface of the immiscible ACM/CPP blend. Increasing the AO80 content can be considered to be the key to solving this problem.

In this study, we examined the additive effects of AO80 on the dynamic mechanical properties of the ACM/ CPP blends. The dynamic mechanical analysis (DMA) as well as differential scanning calorimetry (DSC) was used to investigate the distribution of $\mathrm{AO}-80$ to each phase in the ACM/CPP blends and to confirm the compatibilizing effects of AO-80 in those blends. Scanning electron microscopy (SEM) was used to observe the morphology of those blends, and Fourier transform infrared (FT-IR) spectroscopy has been used to study the nature of the in-

${ }^{\dagger}$ To whom correspondence should be addressed (Tel: 076-234-4813, Fax: 076-234-4829, E-mail: wucf@t.kanazawa-u.ac.jp). 


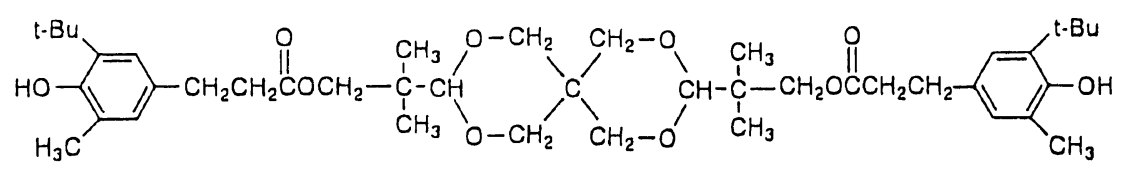

Figure 1. Chemical structure of 3,9-bis [1,1-dimethyl-2 $\{\beta$-( 3-tert-butyl-4-hydroxy-5-methylphenyl) propionyloxy $\}$ ethyl] $-2,4,8,10$ tetraoxaspiro[5,5]-undecane, which is abbreviated as AO-80.

teraction mechanism between $\mathrm{AO}-80$ and polymer. The final goal is to establish a new concept for compatibilizing polymer blends by low-molecular-weight compound with bi-functional hydrogen-bonding accepter.

\section{EXPERIMENTAL}

\section{Materials and Sample Preparation}

The ACM used in this study was commercial grade (Nippon Zeon Co., Nipol AR 51); CPP with 26\% of the weight content of chloride was an adhesion grade (Nippon Paper Industries Co., Superchlon 803LS). The AO80 (as shown in Figure 1) used as a compatibilizer, was a commercial antioxidant (ADK STAB AO-80; Asahi Denka Industries Co.). The glass-transition temperature and melting point of $A O-80$ are 6 and $69,123^{\circ} \mathrm{C}$, respectively, as determined by DSC.

The ACM or/and CPP were kneaded by mixing rollers for $5 \mathrm{~min}$ at $90^{\circ} \mathrm{C}$. And then the $\mathrm{AO}-80$ powders were added to the kneaded ACM and CPP, and their mixture. The kneaded samples were made molten for $3 \mathrm{~min}$ and then were pressed in a laboratory hot press at $160^{\circ} \mathrm{C}$, which is above the melting point of $\mathrm{AO}-80$, for $7 \mathrm{~min}$ under a pressure of $180 \mathrm{~kg} \mathrm{~cm}^{-2}$. Finally, the samples were cooled to obtain films with a thickness of about $1 \mathrm{~mm}$ by quenching into ice-water bath.

\section{$D M A$}

The dynamic mechanical measurements were carried out using a dynamic mechanical analyzer (Rheology Co., DVE-V 4) on sample specimens of the following dimensions: $20 \mathrm{~mm}$ long, $5 \mathrm{~mm}$ wide, and around $1 \mathrm{~mm}$ thick. The temperature dependence of dynamic tensile moduli was measured at a constant frequency of $11 \mathrm{~Hz}$ and at a heating rate of $3^{\circ} \mathrm{C} \min ^{-1}$.

\section{$D S C$}

DSC measurements were carried out with a Mettler Tredo calorimeter DSC 820. Samples about $20 \mathrm{mg}$ in weight and sealed in aluminum were heated from -100 to $160^{\circ} \mathrm{C}$ at a scanning rate of $10^{\circ} \mathrm{C} \mathrm{min}^{-1}$ under a nitrogen atmosphere. The value of the glass transition temperature $\left(T_{\mathrm{g}}\right)$ was identified by the midpoint of the transition region in the DSC curves.

\section{$S E M$}

The section of the samples was coated with gold. Then, the photographs were taken with a Hitachi S-4500 field emission gun scanning electron microscopy (SEM) under the following conditions: a working distance $5 \mathrm{~mm}$, a titling angle $15^{\circ}$, an applied voltage $15 \mathrm{kV}$.

\section{$F T-I R$}

Infrared spectra were obtained from an accumulation of 100 scans at a resolution of $2 \mathrm{~cm}^{-1}$ with a JASCO FT-

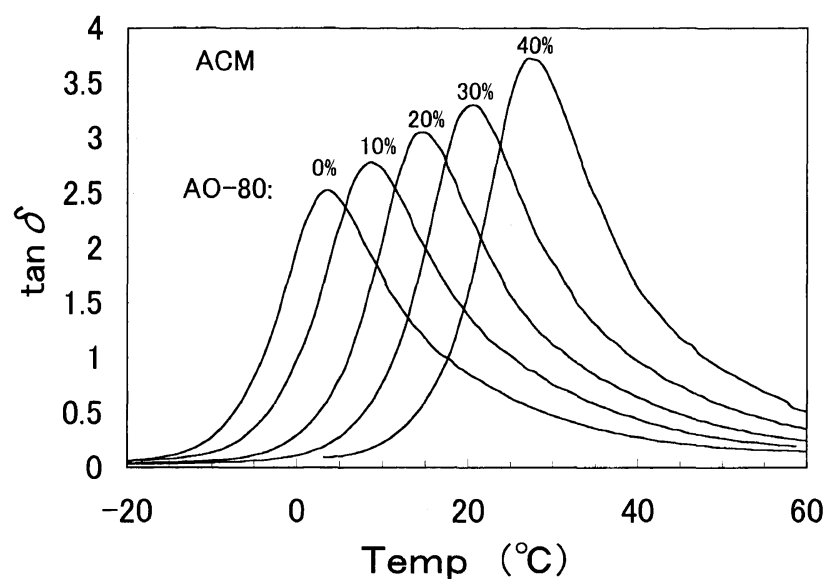

Figure 2. Temperature dependence of $\tan \delta$ at $11 \mathrm{~Hz}$ for ACM and $\mathrm{ACM} / \mathrm{AO}-80$.

IR III spectrometer. The spectra were taken at ambient temperature in $\mathrm{KBr}$. The films used in this study were sufficiently thin $(100 \mu \mathrm{m})$ to be within an absorbency range and were put onto a $\mathrm{KBr}$ disk.

\section{RESULTS AND DISCUSSION}

Figure 2 shows the temperature dependence of the loss tangent $(\tan \delta$ ) for various ACM/AO-80 samples. As shown in the figure, the ACM/AO-80 blends show a single $\tan \delta$ peak associated with $T_{\mathrm{g}}$ of ACM, and the maximum value of the $\tan \delta$ peak increases and its peak location shifts to higher temperatures with increasing the AO-80 content. This behavior is different from that of $\mathrm{CPE} / \mathrm{AO}-80$ system, which shows a novel transition above the glass-transition temperature of $\mathrm{CPE} .^{4-7}$ The peak shift and growth of $\tan \delta$ in the ACM/AO- 80 blends demonstrate that AO-80 is compatible with ACM. Moreover, we note that adding AO-80 into ACM leads to not only an increase in the maximum value of the $\tan \delta$ peak, but also a shift of peak temperature to room temperature, resulting in that ACM/AO-80 mixture is a promising damping-material.

By contrast, in the case of CPP/AO- 80 , as shown in the Figure 3, with increasing the AO-80 content, the maximum value of the $\tan \delta$ peak increases up to $30 \%$ of AO80 , and then the $\tan \delta$ peak becomes smaller and broader above $40 \%$ content of AO- 80 . Those results suggest that when the AO-80 content will be larger than a critical value, consequently a part of AO-80 molecule may show self-aggregation and are reorganized. In this case, a part of the CPP chains are incorporated into the reorganized domains of AO-80. The broader $\tan \delta$ curve will be due to a transition caused by such AO-80-rich domain in addition to glass transition of the CPP-rich phase. 


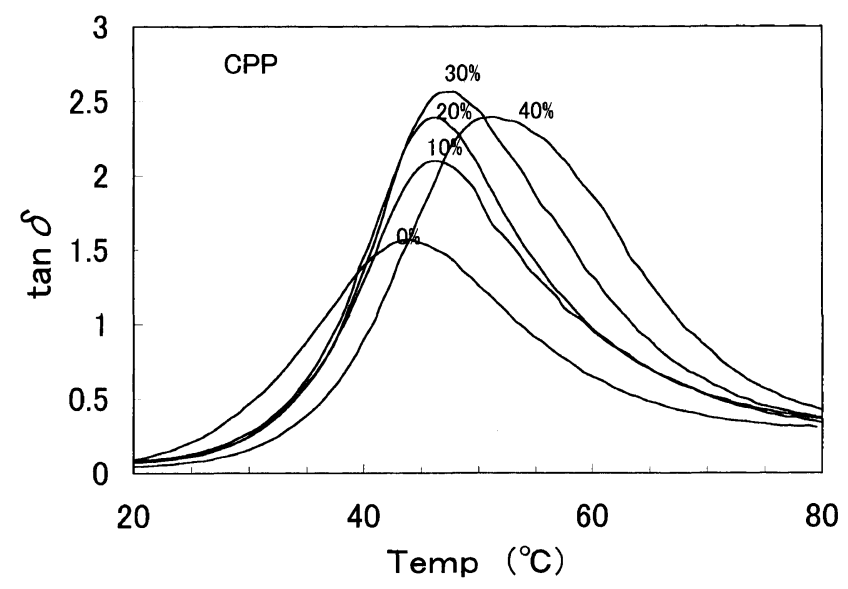

Figure 3. Temperature dependence of $\tan \delta$ at $11 \mathrm{~Hz}$ for CPP and CPP/AO- 80 .

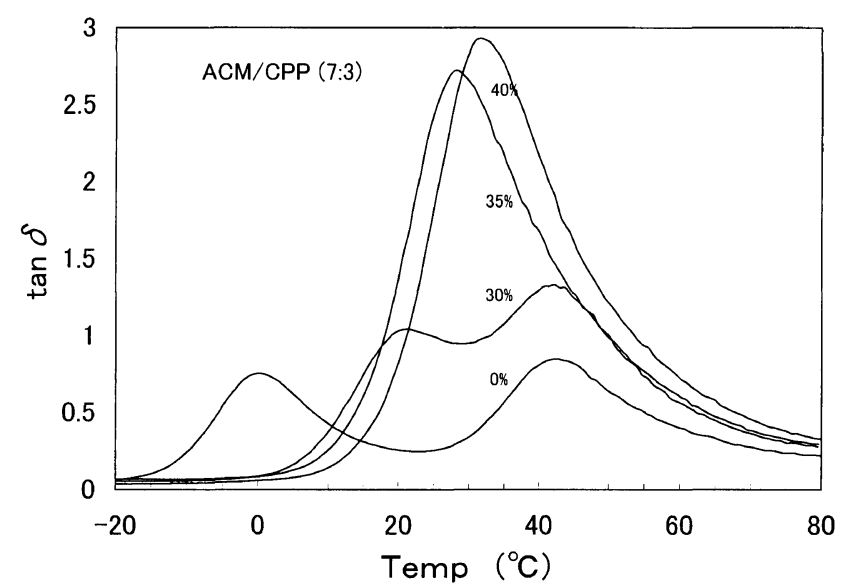

Figure 4. Temperature dependence of $\tan \delta$ at $11 \mathrm{~Hz}$ for ACM/ $\operatorname{CPP}(7: 3)$ with AO-80.

A comparison of ACM/AO-80 with CPP/AO-80 showed that the additive effects of AO-80 on dynamic mechanical properties vary depending on the species of the matrix polymers, and that the intermolecular interaction of AO-80 with ACM is greater than that with CPP.

The additive effects of AO-80 on the $\tan \delta$ curves of a polymer blend of ACM and CPP $(7: 3)$ are shown in Figure 4. As shown in the figure, the ACM/CPP blends exhibit two relatively small peaks. The addition of $30 \%$ AO-80 pronounced these $\tan \delta$ peaks and leads to a higher temperature shift of ACM peak but did not affect the location of CPP peak. These results suggest that the AO-80 molecules may preferentially mixes with ACM polymers. This is possible because the intermolecular interaction of AO-80 with ACM is greater than that with CPP, as demonstrated in Figures 2 and 3. Furthermore, when the AO- 80 content is more than $30 \%$, those ternary blends show only one peak apparently, implying that ACM and CPP are compatibilized by AO- 80 .

Figure 5 shows the temperature dependence of the storage modulus $E^{\prime}$. When the AO-80 content is $30 \%$, the $E^{\prime}$ curve clearly shows two dispersions around 10 and $35^{\circ} \mathrm{C}$, whereas when the AO-80 content is more than $30 \%$, the $E^{\prime}$ show a single dispersion apparently. These findings suggest that the morphologies of the ternary

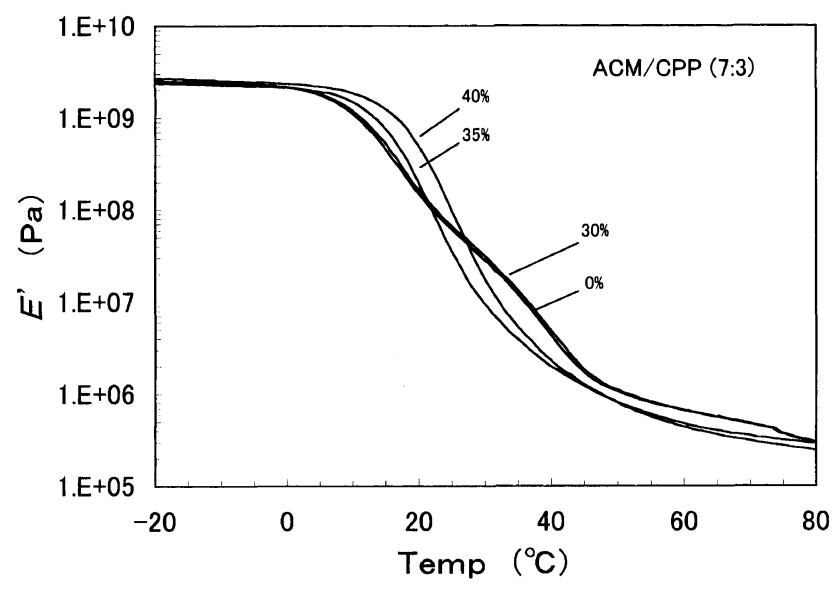

Figure 5. Temperature dependence of $E^{\prime}$ at $11 \mathrm{~Hz}$ for ACM/CPP (7:3) with AO-80.

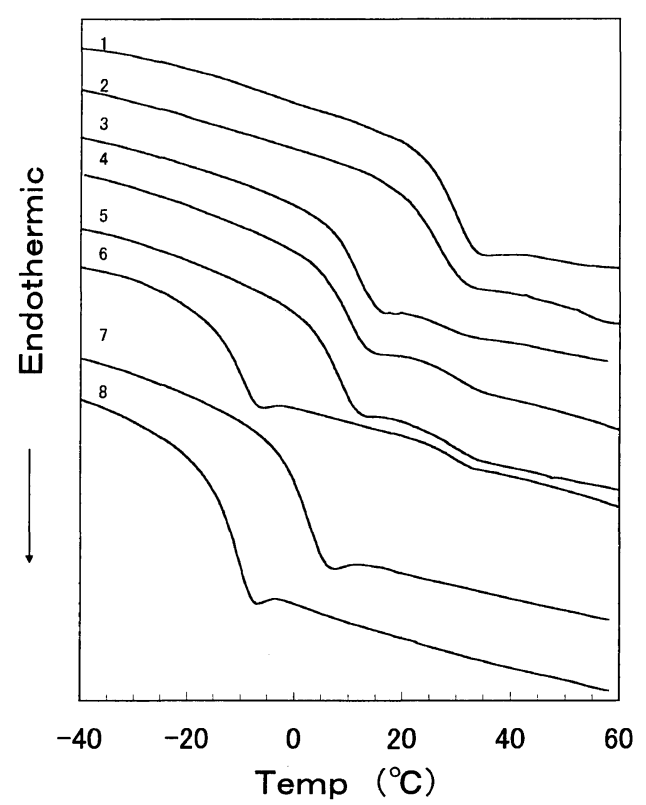

Figure 6. DSC thermograms of various samples at a heating rate of $10^{\circ} \mathrm{C} \mathrm{min}^{-1}$. (1) $\mathrm{CPP}$ with $\mathrm{AO}-80$ (30 wt\%); (2) CPP; (3) ACM/CPP (7:3) with AO-80 (40 wt\%); (4) ACM/CPP (7:3) with AO-80 (35 wt\%); (5) ACM/CPP (7:3) with AO-80 (30 wt\%); (6) ACM/CPP (7:3); (7) ACM with AO-80 (30 wt\%); (8) ACM.

blends of ACM/CPP with AO-80 vary depending on the AO-80 content.

Figure 6 shows the DSC curves of various samples. In the case of binary mixtures (curves 1 and 7), the glasstransition temperatures of two polymers (curves 2 and 8) shift to higher temperature by adding AO-80. In contrast, in the case of ternary mixtures (curves 3-6), when AO-80 added into an immiscible ACM/CPP blend (curve 6), the glass transition of the ACM component greatly shifts to higher temperatures with increasing the AO-80 content, whereas the glass transition of the CPP component hardly changes. This tendency is agreement with a shift in the $\tan \delta$ peak location. Therefore, it seems reasonable to conclude that AO-80 preferentially mixes with polymer ACM. However, an important point to emphasize is that two transitions observed in DSC while only one transition was observed in DMA when 
AO-80 content is 35 and $40 \%$. In general, because the sensitivity of DMA is better than DSC, the transition, which cannot be sensed using DSC, is seen well with DMA. To make difference by this measurement way clear, it thinks that a discussion in terms of the AO-80 distribution into each component of immiscible polymer blend is necessary.

Nishi et $a l .{ }^{19}$ extensively investigated the relationship between the shift of the glass-transition temperature and the distribution of oils in immiscible elastomer blends. They found that the $T_{\mathrm{g}}$ shift of a polymer $\mathrm{A}$ is larger than the value that expected when a uniform distribution of oil is assumed, whereas that of another polymer B is smaller than anticipated value when oil preferentially mixes with polymer A. Identical phenomenon has been observed for some plasticized polystyrenebased ionomers. ${ }^{20}$ Therefore, the distribution state of AO-80 in immiscible ACM/CPP blends can be explained in terms of the shift in the glass-transition temperature.

The additive effects of AO-80 on $T_{\mathrm{g}}$ 's of ACM are plotted against the AO-80 content in Figure 7. For the binary blends of ACM/AO- 80 the $T_{\mathrm{g}}$ (open circle) evaluated from the DSC curves increase linearly as the AO-80 content increases. On the other hand, the $T_{\mathrm{g}}$ (black circle) of the ternary blends of ACM/CPP (7:3) with AO-80 increases linearly also, but it is larger than that of the binary blends of ACM/AO- 80 at the same AO- 80 content. This suggests that AO- 80 prefers to be dissolved in ACM rather than in CPP. The shift in the $T_{\mathrm{g}}$ of the ACM component for the ternary blends can be responsible for an additive effect of AO-80 and a blending effect of CPP. As seen in Figure 7, the $T_{\mathrm{g}}$ (open circle) of pure ACM is almost the same in the $T_{\mathrm{g}}$ (black circle) of ACM component within the ACM/CPP blend, suggesting that the shift in $T_{\mathrm{g}}$ of ACM caused by another polymer component CPP blending can be ignored. Instead of plotting $T_{\mathrm{g}}$ against $\mathrm{AO}-80$ content in ACM/CPP, it is re-plotted against AO80 content in ACM (open square), which is calculated from the amount of the addition of AO-80 by assuming that there is no AO- 80 in CPP. If all AO-80 molecules are dissolved into ACM component, these open square symbols should fall on a line obtained from the data of $\mathrm{ACM} / \mathrm{AO}-80$. It is seen that only the data point with $\mathrm{AO}-$ 80 content of $30 \%$ falls on the line. In this case, all AO-80 molecules seem to be dissolved into ACM phase because the intermolecular interaction of AO-80 with ACM is greater than that with CPP. However, as the AO-80 content increases, the open squares deviate from this line. This result suggests that a part of AO-80 molecules is incorporated into the interfacial layer between ACM and CPP or into the domain of CPP when the AO-80 content is beyond $35 \%$.

According to DSC and DMA studies for a semiinterpenetrating polymer network system consisting of epoxy resin and polyurethane by Li et al.,${ }^{21,22}$ they found a novel transition peak between two glass transitions ascribed by $T_{\mathrm{g}}$ of an interface due to intermolecular hydrogen bonds.

Let us now consider the magnitude of the peak area under the $\tan \delta$-temperature curves, which is abbreviated as TA. The additive effects of AO-80 on the TA values of ACM/CPP are summarized in Figure 8. A sharp increase of the TA value was observed around $30-35 \%$

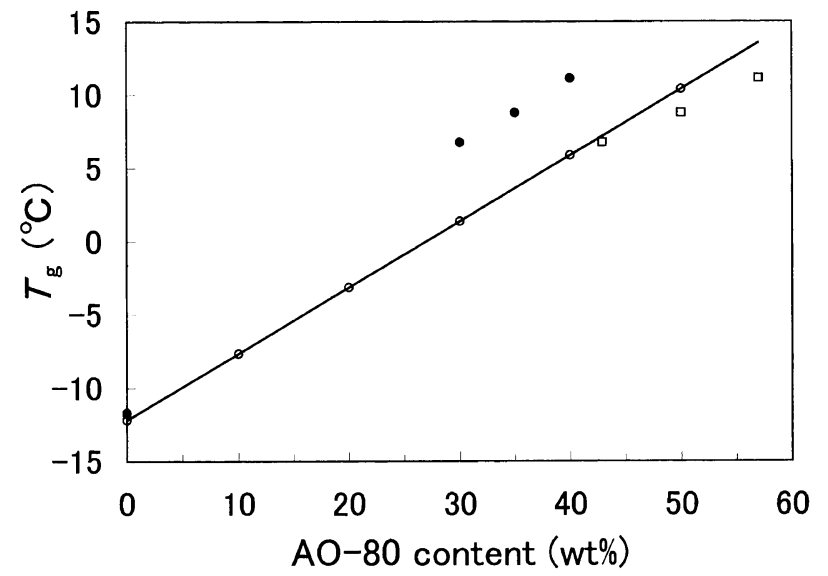

Figure 7. Dependence of the glass-transition temperature of ACM measured by DSC on the AO-80 content.

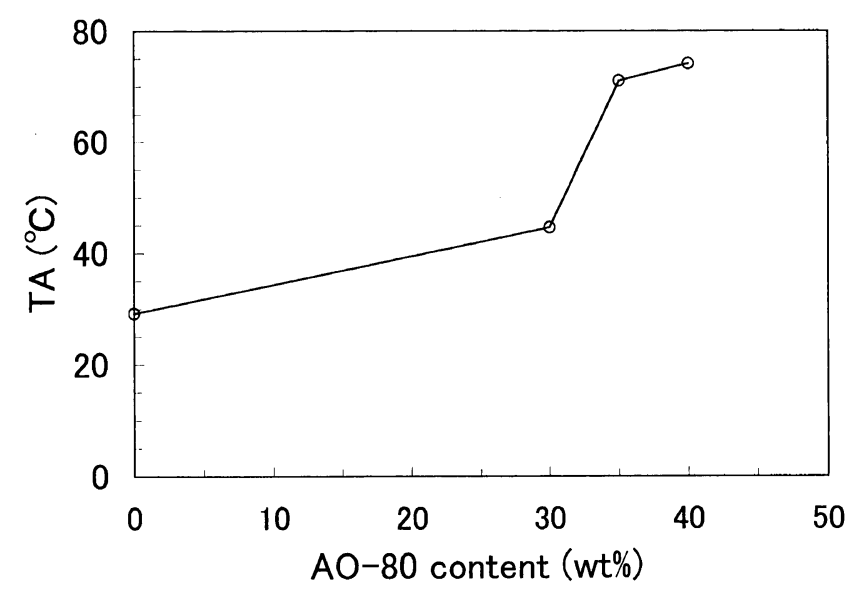

Figure 8. Dependence of the peak area under the $\tan \delta$ temperature curves of various samples on the AO-80 content.

of the AO- 80 content. This may be due to the appearance of a new $\tan \delta$ peak between both glass transitions of $\mathrm{ACM}$ and CPP, and it can be attributed to the formation of an interfacial layer between ACM and CPP.

As is evident from Figure 4, the shape of $\tan \delta$ temperature curves is drastically changed at around 30 $-35 \%$. A blend of $30 \%$ AO- 80 shows distinctly two peaks whereas that of $35 \% \mathrm{AO}-80$ seems to have a broad peak with multi-components. In order to quantitatively analyze the $\tan \delta$ peaks, we performed a mathematical deconvolution process, in which the gaussian curves are used. As seen in Figure 9, we found one relatively larger peak between two peaks corresponding to glass transition of ACM and of CPP for the ACM/CPP (7:3) with $35 \%$ AO-80. This peak is probably associated with an interfacial layer between ACM and CPP. Considering that the novel peak is detectable only from DMA and DSC curve not shows such peak, this novel peak can be considered to being due to the cooperative motion between the AO-80 molecules and the ACM chains as well as the CPP chains.

We have two important facts: (1) is that the AO-80 molecules can form the hydrogen bonds not only with ACM but also with CPP; (2) is that AO-80 can be considered to be a bi-functional hydrogen-bonding acceptor. 


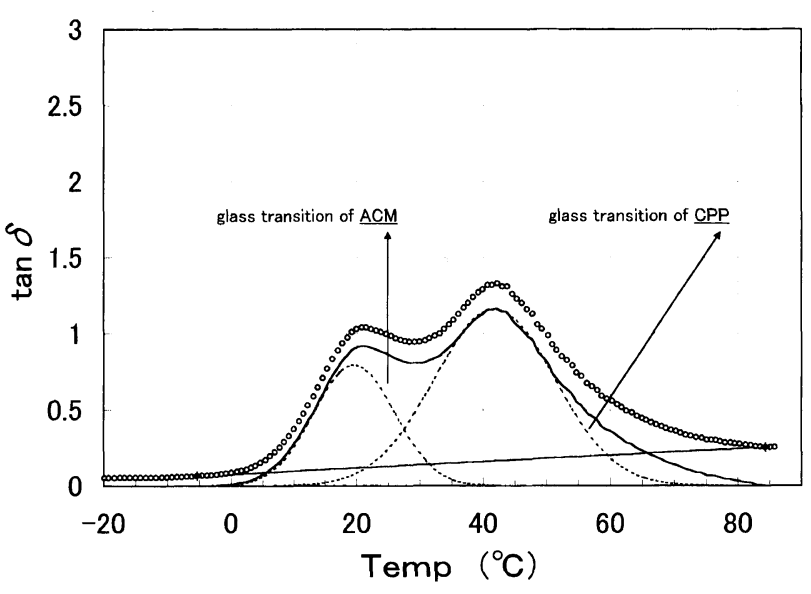

(a)

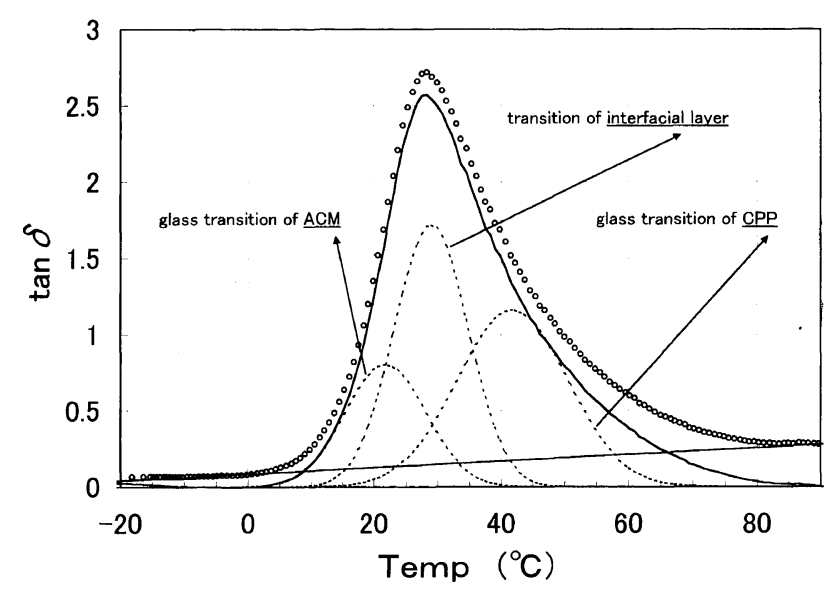

(b)

Figure 9. Normalized tan $\delta$-temperature curve of (a) ACM/CPP $(7: 3)$ with AO-80 (30\%), and (b) ACM/CPP (7:3) with AO-80 (35\%). Gaussian curves are shown using dotted lines.

When a small amount of AO-80 added to ACM/CPP, the AO-80 molecules were preferentially dissolved into an ACM component because the compatibility of AO-80 with ACM is larger than that with CPP. However, as the AO-80 content increase, the number of the free carbonyl groups decreases gradually because of the formation of the hydrogen bond between the hydroxyl groups of AO80 and the carbonyl groups as well as the hydroxyl groups of ACM. When the AO- 80 content is large enough, it is conceivable that a part of AO-80 hydroxyl groups form the hydrogen bond together with the $\alpha$ hydrogen at the surface of the CPP domain, thus, a super-molecular network can be formed, as shown in Figure 10. Consequently an interfacial layer can be considered to be consisting of such super-molecular network.

To confirm the formation of the hydrogen bond, we performed the FT-IR measurement of various samples. The spectrum of AO- 80 shows two significant absorptions of the hydroxyl group $(\mathrm{OH})$ stretching region $(3400$ $\left.-3800 \mathrm{~cm}^{-1}\right)$ and carbonyl group $(\mathrm{C}=\mathrm{O})$ stretching region $\left(1650-1850 \mathrm{~cm}^{-1}\right)$. Because the bands for the $\mathrm{C}=\mathrm{O}$ group stretching vibration is complicated (too abundant), here, we focus on the $\mathrm{OH}$ group-stretching region

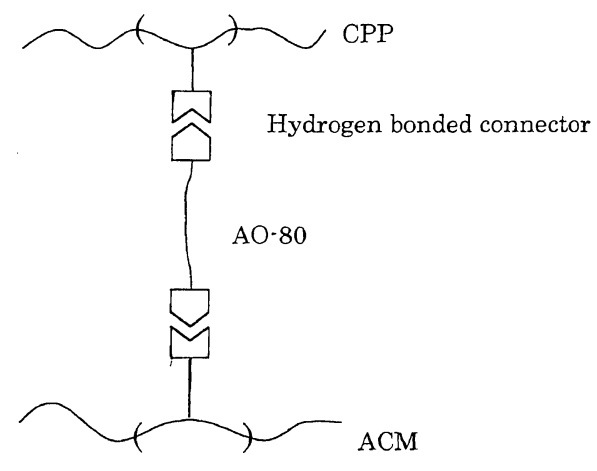

Figure 10. Schematic structure of supermolecular at an interface between ACM and CPP.

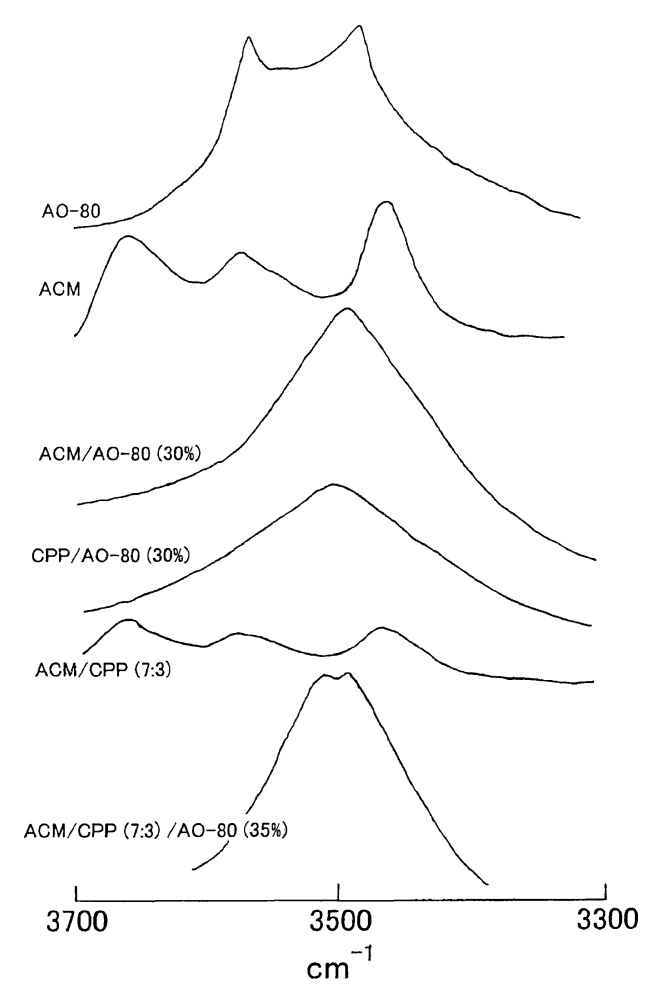

Figure 11. Infrared spectra of various samples in the hydroxylstretching region.

$\left(3400-3800 \mathrm{~cm}^{-1}\right)$.

Figure 11 shows the infrared spectra centered near $3500 \mathrm{~cm}^{-1}$ corresponding to $\mathrm{OH}$ groups for various samples. A salient feature of the spectrum of pure $\mathrm{AO}-80$ is the presence of two bands associated with the $\mathrm{OH}$ group stretching vibration. The band at $3567 \mathrm{~cm}^{-1}$ is assigned to "free" (non-hydrogen-bonded), whereas the band at $3482 \mathrm{~cm}^{-1}$ is assigned to " $\mathrm{OH}-\mathrm{OH}$ " (hydrogen-bonded) between AO-80 molecules, respectively. For the binary blends of ACM/AO-80 (30\%) and CPP/AO-80 (30\%) these bands disappeared, but other two bands clearly appeared at 3493 and $3504 \mathrm{~cm}^{-1}$, respectively. These bands of 3493 and $3504 \mathrm{~cm}^{-1}$ can be attributed to an intermolecular hydrogen bond between $\mathrm{AO}-80$ and $\mathrm{ACM}$ or CPP. Moreover, comparing ACM/AO-80 and CPP/AO80 , we also observed that the wavenumber of ACM/AO80 are lower than that of CPP/AO-80. This confirms that the intermolecular interaction of AO-80 with ACM is 


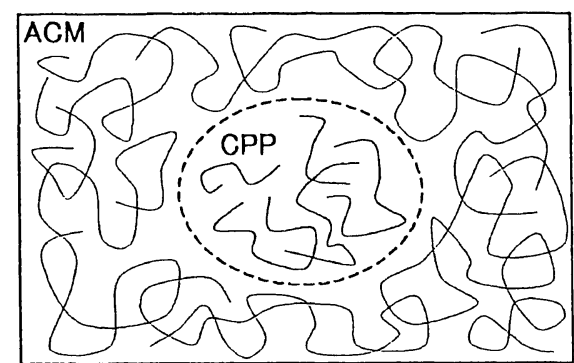

(a)

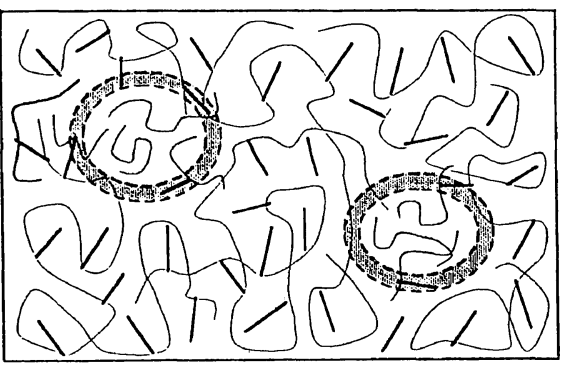

(c)

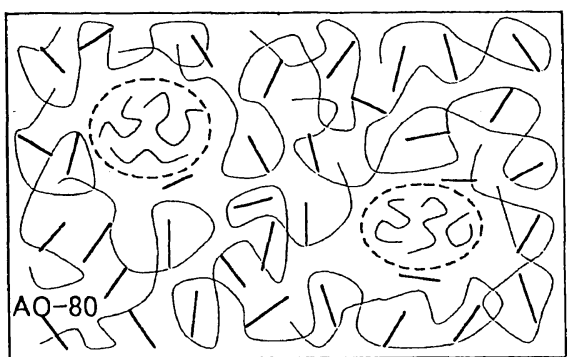

(b)

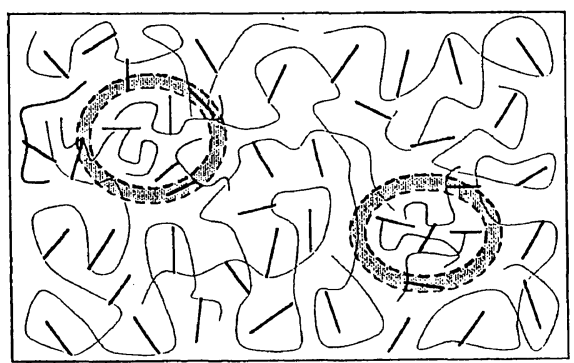

(d)

Figure 12. Schematic representation of various possible state of ACM/CPP blends with AO-80. (a) ACM/CPP (7:3). Phase-separated state. (b) ACM/CPP (7:3) with AO-80 (30\%). ACM/CPP is incompatible, and the AO-80 molecules are preferentially dissolved to the ACM continuous phase. (c) ACM/CPP (7:3) with AO-80 (35\%). An interface between ACM and CPP is formed. (d) ACM/CPP (7:3) with AO-80 (40\%). The AO-80 molecules are also dissolved in the CPP domains.

(a)

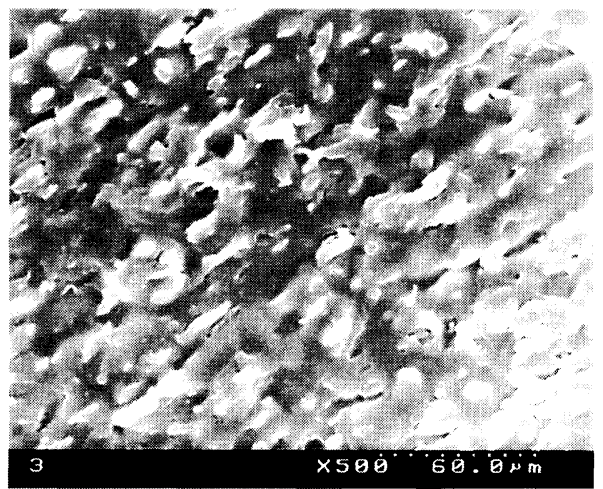

(c)

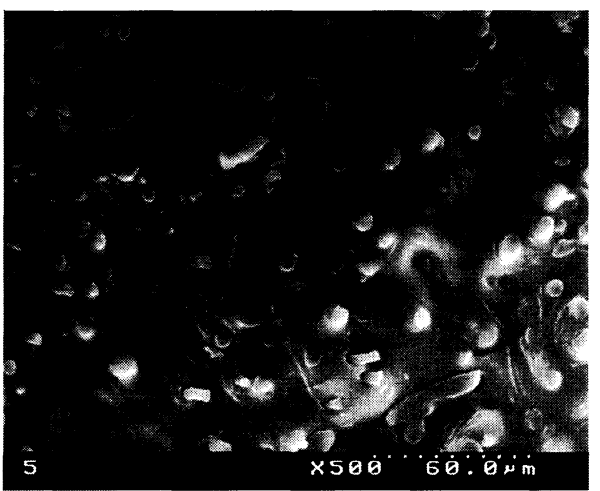

(b)

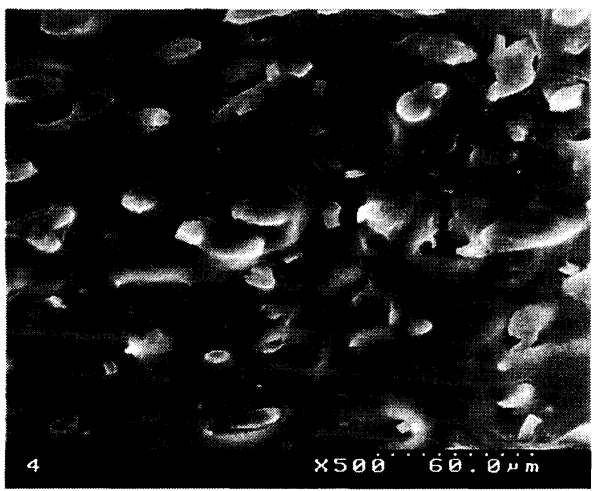

(d)

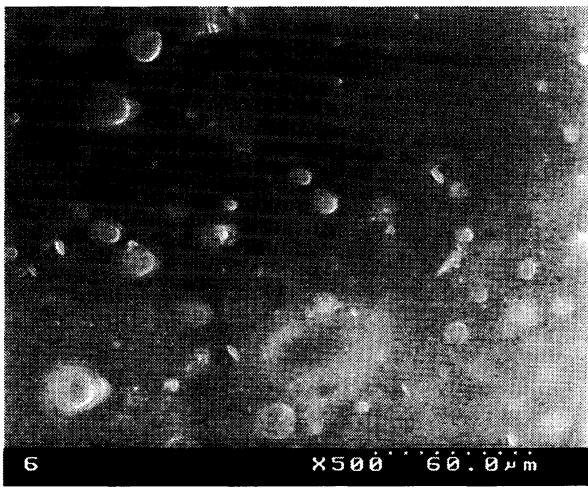

Figure 13. SEM photographs of various samples: (a) ACM/CPP (7:3); (b) ACM/CPP (7:3) with AO-80 (30\%); (c) ACM/CPP (7:3) with AO80 (35\%); (d) ACM/CPP (7:3) with AO-80 (40\%).

larger than that with CPP.

On the other hand, as seen in figure, pure ACM exhibits three bands on the range from 3300 to $3700 \mathrm{~cm}^{-1}$. Those bands in order of descending wavenumber are assigned to "free" (non-hydrogen-bonded), "OH-OH" Polym. J., Vol. 33, No. 4, 2001 (hydrogen-bonded) between acrylic acid units, and another band which may be attributed to the $\mathrm{O}-\mathrm{H}$ stretching vibration associated with an interaction between the $\mathrm{OH}$ groups and the metallic ions (the metallic salt often used as a kind of coagulant for ACM), respectively. Even if CPP is added to ACM, the position of these bands 
hardly changes. This implies that the $\mathrm{OH}$ group of ACM cannot form hydrogen bond with the $\alpha$-hydrogen of CPP.

For the ternary blends of ACM/CPP (7:3) with AO-80 (35\%) three bands of ACM disappeared, but two additional bands appeared at 3493 and $3504 \mathrm{~cm}^{-1}$, respectively. These two bands seem to be the same with those observed in two binary blends of ACM/AO-80 and CPP/ AO-80. Therefore, they may be attributed to an intermolecular hydrogen bond between AO-80 and ACM or CPP. Those FT-IR results also demonstrate the existence of a super-molecular network shown in Figure 10.

The novel peak showed in Figure $9 \mathrm{~b}$ is very useful also in improving the damping properties. The TA value can be considered to be a damping index, which is a measure of the energy dissipation of materials. ${ }^{23,24}$ As seen in Figure 8, small change in the AO-80 content from $35 \%$ to $30 \%$ causes a great increase (ca. $60 \%)$ in the TA value, and above $35 \%$ of the AO- 80 content the TA values gradually increase. Moreover, comparing with many interpenetrating polymer networks (IPNs) ${ }^{25-27}$ having two overlapping peaks, it is found that those systems highly adding AO-80 exhibit top-ranking TA value. Thus, the present blends make it possible to provide us very good damping materials.

It is also found from Figure 4 that a $\tan \delta$ peak corresponding to the glass-transition of the CPP component remained the constant until $35 \%$, but further increase in the AO-80 content (until $40 \%$ ) leads this peak to shift higher temperatures. This suggests that an excess of AO-80 molecules probably be also dissolved into the domains of CPP when the AO-80 molecules are saturated.

In summary, the images of the distribution of AO-80 to each phase of an immiscible blend of ACM and CPP can be illustrated in Figure 12. The morphologies of a ternary blend of ACM/CPP with AO-80 vary depending on the AO-80 content. The molecular mechanism underlying various $\tan \delta$-temperature behavior showed in Figure 4 can be explained reasonably on the basis of this speculation.

The morphologies findings from DMA, DSC, and FTIR for the ternary blends of ACM/CPP with AO-80 were confirmed by electron microscopy. The SEM micrographs showed significant changes in the morphologies (Figure 13). The unadded ACM/CPP (7:3) showed white prolonged CPP domains and gray ACM matrix. The CPP domain sizes were about $30 \mu \mathrm{m}$ in length and about $6 \mu \mathrm{m}$ in width, respectively. At 30\% AO-80 content, the shape of the CPP phase domains hardly changed though their sizes became a little small. At $35 \%$ AO-80 content, a substantial change in morphology occurred. The domains of the CPP phase become spherical from prolonged form. When the AO-80 content further increase to $40 \%$ the CPP domains hardly changed in the size and shape, but their boundary became indistinct.

Moreover, a localized change in a domain structure shows in Figure 14. While for the 30\% added sample the CPP domain clearly separated from the ACM matrix, for the $35 \%$ added sample the circumference of the CPP domain formed an interconnected interface. In addition, when the AO- 80 content is $40 \%$, the sample showed indistinct CPP domain. These facts demonstrated the existence of an interfacial layer between ACM and CPP when the AO-80 content is more than $35 \%$. Conse- (a)

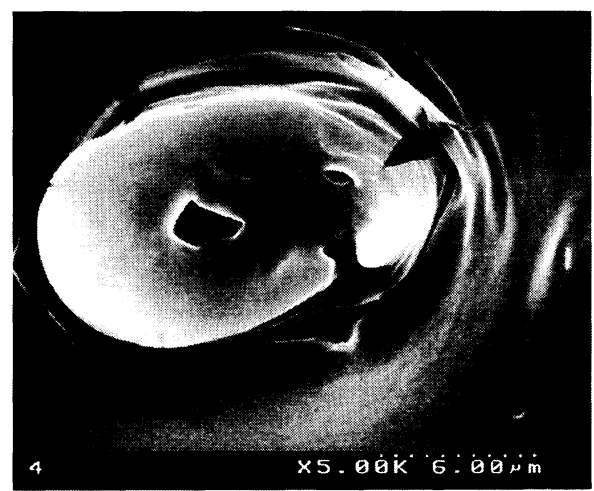

(b)

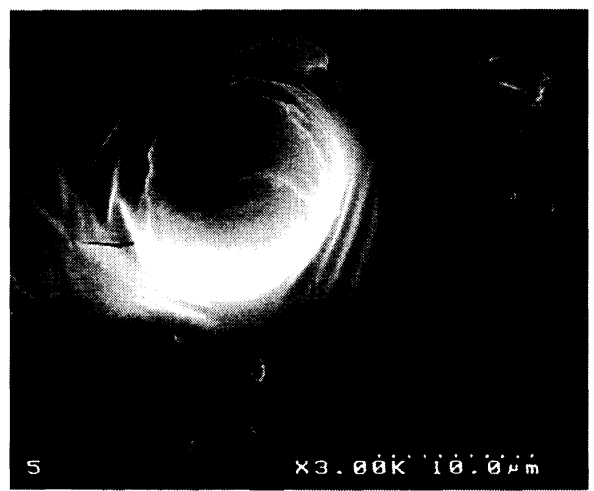

(c)

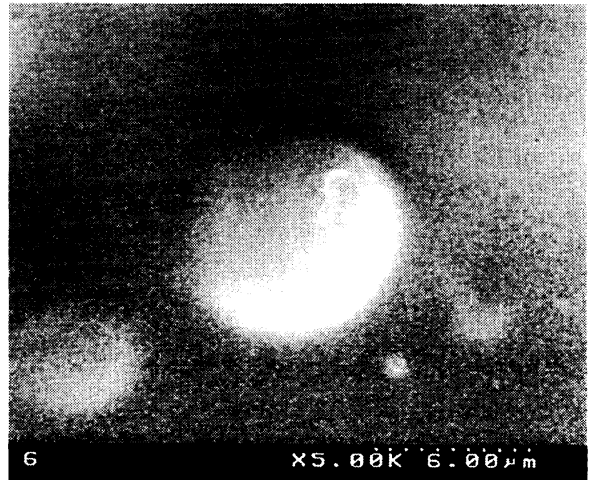

Figure 14. SEM photographs of various samples: (a) ACM/CPP ( $7: 3$ ) with AO-80 (30\%); (b) ACM/CPP (7:3) with AO-80 (35 wt\%); (c) ACM/CPP (7:3) with AO-80 (40\%).

quently, there is considerable validity in structural image shown in Figure 12.

\section{CONCLUSIONS}

The dynamic mechanical properties for the binary blends of ACM and CPP with AO-80, and their ternary systems were investigated. The maximum value of the $\tan \delta$ peak of ACM and CPP increases, and their peak location shifts to a higher temperature by adding AO-80. In contrast, the dynamic mechanical properties for the ternary blends of ACM/CPP (7:3) with AO-80 vary depending on the AO-80 content: when the AO-80 content is $30 \%$ the ternary blend show two peaks, whereas when the AO-80 content top $35 \%$ show only one peak apparently.

The distribution of AO-80 in immiscible ACM/CPP blend was examined by a shift in glass-transition temperature. As a result, the morphologies of those ternary blends depend also on the AO-80 content. When the AO- 
80 content is lower than $30 \%$ the AO- 80 molecules are preferentially distributed to a continuous ACM phase, whereas as the AO-80 content increases, a part of $\mathrm{AO}-80$ molecules are incorporated to the interfaces between ACM and CPP, and then to the domains of CPP. In addition, the SEM observation demonstrated the reduction in the domain size of CPP due to the addition of AO-80.

Separating the $\tan \delta$-temperature curve of a ternary blend of ACM/CPP (7:3) with AO-80 (35\%) showed a novel $\tan \delta$ peak that is undetectable from DSC between two peaks corresponding to ACM and CPP. This peak is attributed to an interfacial layer where a supermolecular network is formed. The existence of such super-molecular network was also suggested by infrared spectrum. As a result, a ternary blend of ACM/CPP with more AO-80 was found to be a very good damping material because of the appearance of the novel $\tan \delta$ peak.

\section{REFERENCES}

1. O. Olabisi, L. M. Robeson, and M. T. Shaw, in "Polymer-Polymer Miscibility”, Academic Press, New York, N.Y., 1979.

2. L. A. Utracki, in "Polymer Alloys and Blends", Hanser Publishers, London, 1989.

3. D. R. Paul, in "Polymer Blends", D. R. Paul and S. Newman, Ed., Academic Press, New York, N.Y., 1978, vol. 2, chapt. 12.

4. C. Wu, T. Yamagishi, Y. Nakamoto, S. Ishida, K. Nitta, and S Kubota, J. Polym. Sci., Part B: Polym. Phys., 38, 2285 (2000).

5. C. Wu, T. Yamagishi, Y. Nakamoto, S. Ishida, K. Nitta, and S Kubota, J. Polym. Sci., Part B: Polym. Phys., 38, 2943 (2000).

6. C. Wu, T. Yamagishi, Y. Nakamoto, S. Ishida, K. Nitta, and S. Kubota, Kobunshi Ronbunshu, 57, 294 (2000).

7. C. Wu, J. Polym. Sci., Part B: Polym. Phys., 39, 23 (2001).

8. C. Wu, J. Appl. Polym. Sci., in press.
9. C. Wu, T. Yamagishi, Y. Nakamoto, S. Ishida, K. Nitta, and S. Kubota, J. Polym. Sci., Part B: Polym. Phys., 38, 1496 (2000).

10. C. Wu and K. Nitta, Kobunshi Ronbunshu, 57, 449 (2000).

11. C. Wu, T. Nomura, T. Mihara, and K. Hashimoto, U. S. Pattent 09363749 (Jul. 30, 1999).

12. J.-S, Kim, S. B. Roberts, A. Eisenberg, and R. B. Moore, Macromolecules, 26, 5256 (1993).

13. P. Michel, C. G. Bazuin, and J. Robert, Macromolecules, 28 , 1567 (1995).

14. R. D. Lundberg, H. S. Makowski, and L. Westerman, Adv. Chem. Ser., 187, 67 (1980).

15. C. G. Bazuin and A. Eisenberg, J. Polym. Sci., Polym. Phys. Ed., 24, 1137 (1986).

16. J. J. Fitzgerald, D. Kim, and R. A. Weiss, J. Polym. Sci., Polym. Lett. Ed., 24, 263 (1986).

17. J. J. Fitzgerald and R. A. Weiss, J. Polym. Sci., Polym., Phys. Ed., 28, 1719 (1990).

18. R. A. Weiss, J. J. Fitzgerald, and D. Kim, Macromolecules, 24, 1064 (1991).

19. K. Naito, N. Wada, S. Inoue, and T. Nishi, J. Appl. Polym. Sci., 61, 755 (1996).

20. J.-S. Kim, S. B. Roberts, A. Eisenberg, and B. M. Robert, Macromolecules, 26, 5256 (1993).

21. Y. Li and S. Mao, J. Polym. Sci., Part A: Polym. Chem., 34, 2371 (1996).

22. Y. Li and S. Mao, J. Appl. Polym. Sci., 61, 2059 (1996).

23. T. Ogawa and T. Yamada, J. Appl. Polym. Sci., 53, 1663 (1994).

24. R. Hu, V. L. Dimonie, M. S. El-aasser, R. A. Pearson, A. Hiltner, S. G. Mylonakis, and L. H. Sperling, J. Polym. Sci., Part B: Polym. Phys., 35, 1501 (1997).

25. M. C. O. Chang, D. A. Thomas, and L. H. Sperling, J. Appl. Polym. Sci., 34, 409 (1987).

26. Q. Chen, H. Ge, D. Chen, X. He, and X. Yu, J. Appl. Polym. Sci., 54, 1191 (1994).

27. D. J. Hourston and F. U. Schafer, J. Appl. Polym. Sci., 62, 2025 (1996). 